\title{
Development of brake caliper for rally-car
}

\author{
Ádám Horváth ${ }^{1}$, Zoltán Csík ${ }^{2}$, Jacob Sukumaran ${ }^{3}$, Patric Neis ${ }^{4}$, Mátyás Andó ${ }^{1, *}$ \\ ${ }^{1}$ Szent Istvan University, Faculty of Mechanical Engineering, Prater K. ut 1., H-2100, Godollo, Hungary \\ ${ }^{2}$ Gepesz Tuning Ltd., Bobitas ut 26. H-1164 Budapest, Hungary \\ ${ }^{3}$ Ghent University, Laboratory Soete, Technologiepark Zwijnaarde 903, B-9052 Zwijnaarde, Belgium \\ ${ }^{4}$ Universidade Federal do Rio Grande do Sul, Sarmento Leite 425, Porto Alegre 90050-170, Brazil \\ ${ }^{*}$ corresponding author
}

\begin{abstract}
We have succeeded to work out a designing-controlling-manufacturing process by which it can be manufactured a given special brake calipers with extremely short transit time. We have dealt with elaborating such finite element background during working out the process in which the new constructions can be simulated to deformation reliably. We have reached this by creating suitable material models and boundary conditions which we identified after manufacturing the prototype. We have also established a separate model-system for optimizing the brake pad beside the caliper opening, based on which the optimal piston diameter and its position can be determined, too. The basic standpoint was the proper change following at developing the process because of the CADCAE-CAM-CNC systems and their proper connections.
\end{abstract}

As a result of this system the rally brake calipers can be made quickly, reliably and economically for different racing cars.

\section{INTRODUCTION}

During car racing it is an important standpoint to produce not only the greater engine output but the greater braking force, too. The greater braking force can be guaranteed by modifying the brake system which includes the change of the brake master cylinder, the brake pipes, the brake discs, the brake calipers and the brake pads, too [1,2]. Among these the change of the brake caliper causes the greatest problem, well this guarantees connection between the stud-stands and brake discs corresponding with different factory standards $[3,4]$. To assembly the high-power brake calipers often meets with difficulties because of lots of wheel knuckle, which have differences of joining points (bolt fastening) respectively $[5,6]$. These problems can be treated in case of luck by manufacturing individual supports [7] which means often compromise, its increases substantially the purchasing time and cost respectively, too. One alternative of this can be such designing-checking-manufacturing process that can be changed flexibly by which the individual claims can be satisfied properly.

The appearance of the software supporting the engineering work was indispensable to take place the above conception in which it can be produce such parametric model-system at which changing some parameters the developed geometry can be adjusted to the given racing car. Because of the property and personal safety it is needed to submit to analysis the changed parametric 3D model in each case so to be convinced of that the mechanism operates safely. Following the designing and checking the CAM software can follow the changes automatically so during minimal time new CNC programs can be made based on the new part. This designing-checking-manufacturing system provides extremely short transit times and high reliability. However the models (3D body-model, material model, finite element boundary conditions, manufacturing parameters...) has to be worked out in more detailed form as in traditional cases, that is the working up of the process requires substantially greater resource.

We would like to present a suitable survey from the process of developing a rally brake caliper in the article, which means a marketable solution between the present economic relations.

\section{MATERIAL AND METHOD}

We have applied mainly engineering software during designing the brake caliper. The parametric 3D model was made in Solid Edge V20-version, which model constituted the basis of further finite element calculations. The finite element calculations were made by the Ansys software, by which we checked the mechanical and tribological characteristics alike, too. We generated the NC-file 
constituting the basis of CNC machining with the EdgeCAM 2010R1 software. The manufacturing was carried out by the DMG DMC 635 C-type three axis CNC milling machine.

The material of the prototype was the 7075-T6 high-strength aluminium. Table 1. shows its characteristics. This material is used among others for aircraft profiles, for gear-shafts, for rocket parts, too.

Table 1. The 7075-T6 aluminium characteristics [8]

\begin{tabular}{|l|l|}
\hline Physical characteristics: \\
\hline Density & $2,81 \mathrm{~g} / \mathrm{cm}^{3}$ \\
\hline Brinnel-hardness & 150 \\
\hline Rockwell A-hardness & 53,5 \\
\hline Vickers-hardness & 175 \\
\hline Tensile strength & $572 \mathrm{~N} / \mathrm{mm}$ \\
\hline Upper yield strength & $503 \mathrm{~N} / \mathrm{mm}$ \\
\hline Elongation at break & $11 \%$ \\
\hline Elastic modulus & $71,7 \mathrm{GPa}$ \\
\hline Poisson's ratio & 0,33 \\
\hline Thermal characteristics & $2,361 /{ }^{\circ} \mathrm{C} \times 10^{-3}$ \\
\hline $\begin{array}{l}\text { Coefficient of thermal } \\
\text { expansion }\end{array}$ & $0,960 \mathrm{~J} / \mathrm{g} \times{ }^{\circ} \mathrm{C}$ \\
\hline $\begin{array}{l}\text { Coefficient of thermal } \\
\text { expansion }\end{array}$ & $130 \mathrm{~W} / \mathrm{m} \times \mathrm{K}$ \\
\hline Thermal conductivity
\end{tabular}

We have carried out opening tests on the prototype brake caliper to which we set up individual measuring system. Figure 1 . shows the measuring system. The brake caliper, the oil-pipeline the pressure intensifier, the distance block and the manometer were the main parts of the measuring system. The mechanical operation pressure intensifier produces the load of the brake caliper which is connected to the brake caliper. Before starting the measuring we placed the metal block with proper rigidity replacing the brake pads and the brake disc in the brake caliper. After filling the mechanical pressure intensifier, the pipeline and the brake caliper the measuring system has to be bled, then it has to be loaded with the maximum pressure several times before starting the opening measurings that the brake caliper should get operation condition. The brake pressures measured on racing car at earlier racing circumstances (without brake-helping equipment) were the followings: $0,5-1 \mathrm{MPa}$ at slight braking, 2-3 MPa at medium braking, 5-7 MPa at strong braking and 8-9 $\mathrm{MPa}$ at emergency braking. Based on this we considered as maximum $17 \mathrm{MPa}$ value of pressure for the tests which means at least double factor of safety already on the level of imposing of load, too. We measured the measurings with 2MPa stops between 1-17 MPa. We measured the brake caliper opening in seven cross-section with Mitutoyo high-accuracy digital gauge. We repeated the measurings three times because of the accidental measuring and data recording errors. Thanked to the repetitions we identified (with T-test) the measuring - and data recording errors which we also excluded from the measuring values.

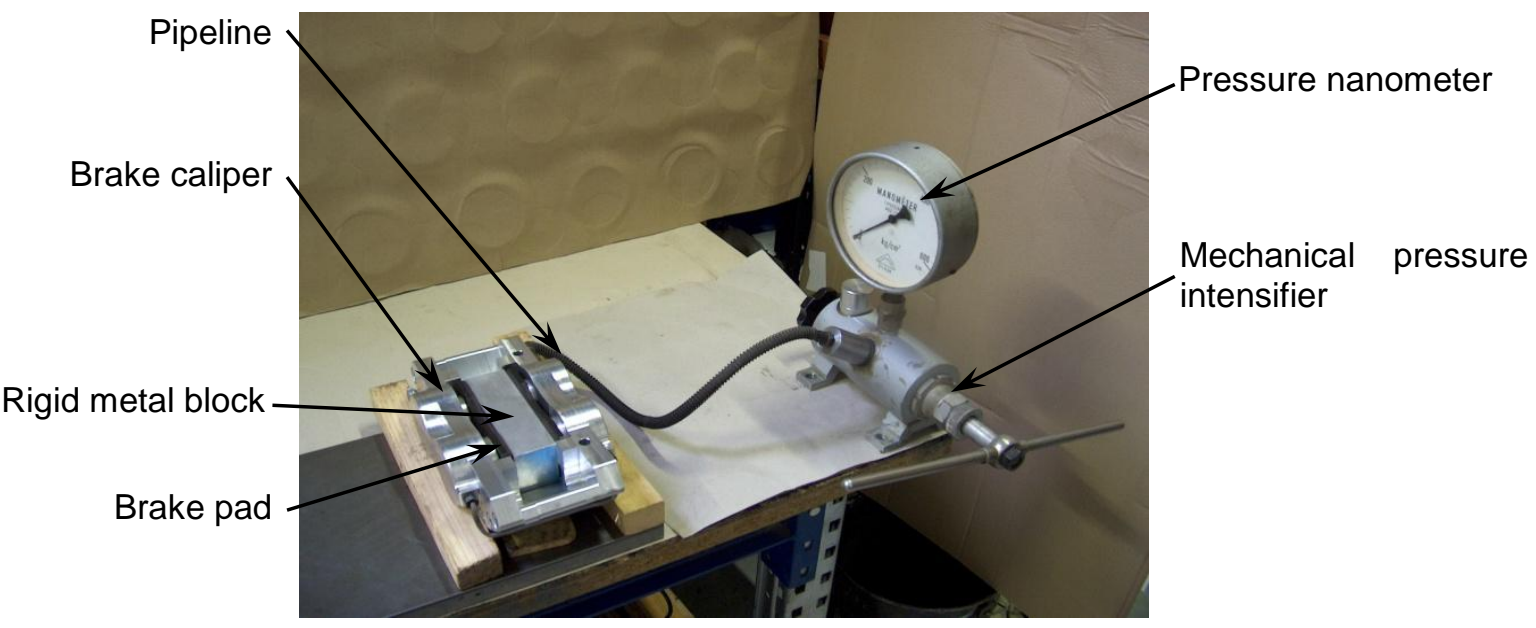

Figure 1. The picture of the measuring system. 
Figure 2. shows the process of developing rally brake caliper.

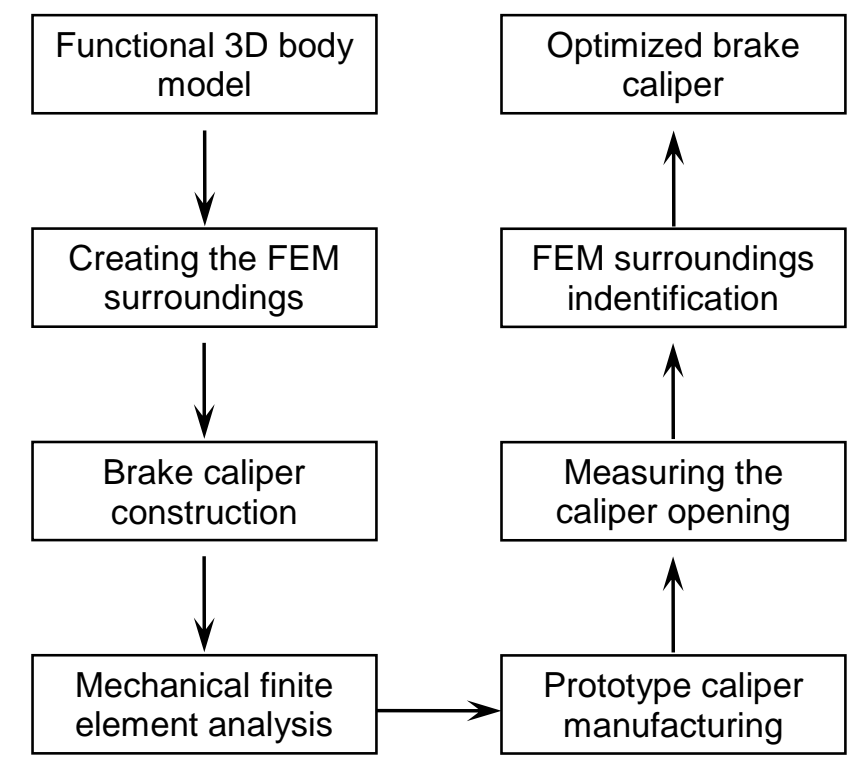

Figure2. Strength development of rally brake caliper.

We started to form a simple functional model during development which was based on the construction of existing brake caliper. We could tested both the CAD and finite element (FEM) surroundings with created 3D functional body model. After successful tests we started to form the real brake caliper-construction. The forming happened in more steps, we checked with finite element analysis the raising stress and the produced deformation after each important change (Figure 3.)

$a$,

Equivalent Stress

Type: Equivalent (von-Mises) Stress Unit: $\mathrm{MPa}$

Time: 1

2009.11.19. 15:44

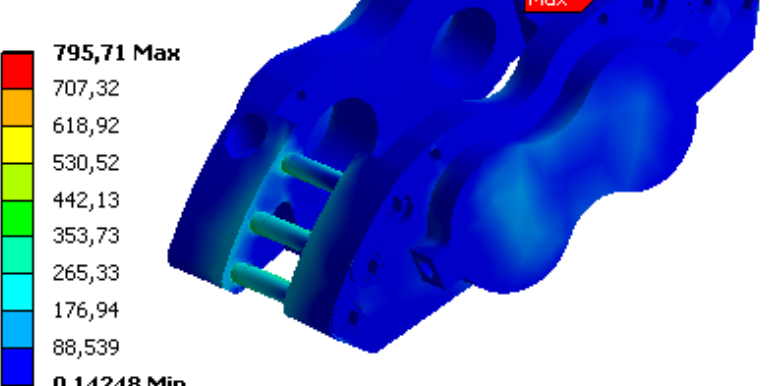

0,14248 Min

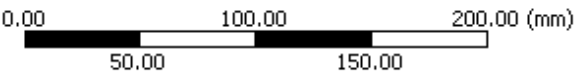

b,

Total Deformation

Type: Total Deformation

Unit: $\mathrm{mm}$

Time: 1

2009.11.19. 15:45

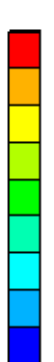

$\square$

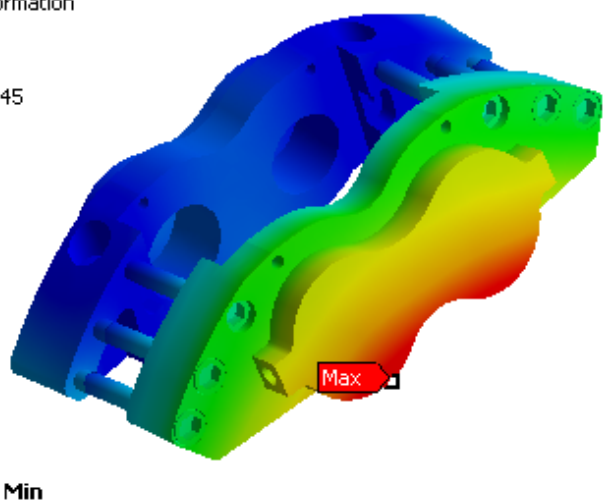

0.00
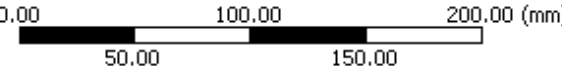

Figure3. The result of finite element analysis ( $a$, stress, b, deformation).

We continued the modifying steps until we didn't find the construction suitable for prototype manufacturing. It was basic standpoint during the prototype production planning to produce such setups in the CAM software to be able to follow the model change. As an effect of this generating the needed machining program of later brake caliper constructions needs minimal time, that is it reduces the manufacturing time significantly. It generates a NC-file according to the setups with CAM-system 
(tool paths-Figure 4.) that the CNC machine can receive and interpret. The manufacturing of the workpiece takes place on the basis of the program to be in the NC-file after these.

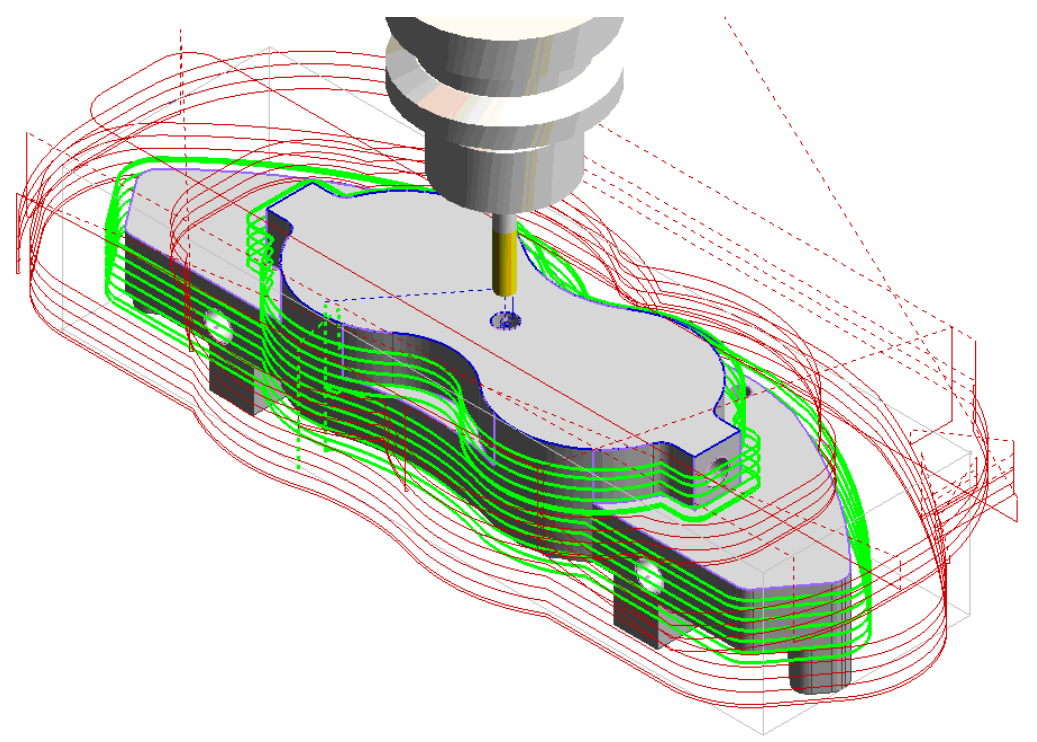

Figure4. Defined tool-paths at one of the workpiece clamping.

We measured the caliper opening with the help of measuring system after manufacturing the prototype. (Figure 5.)

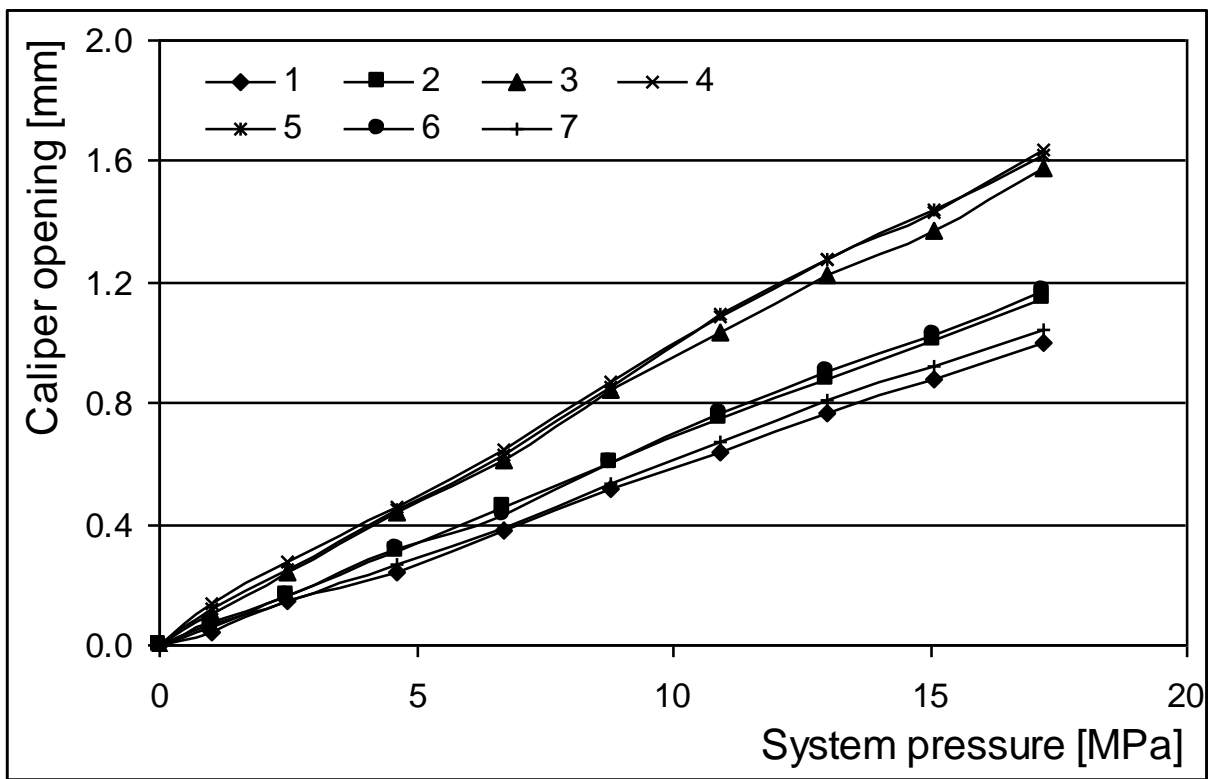

Figure 5. The caliper opening in the measuring cross-section.

It can be seen on the diagram that the dangerous openings were in the third (3), fourth (4) and the fifth (5) cross-sections. These cross-sections can be found in the middle of the brake caliper we measured among the cross-sections, in smallest quantity, but the greatest values in the fourth (4) cross-section, so we compared its values with the results got during the simulation (Figure 6.) 


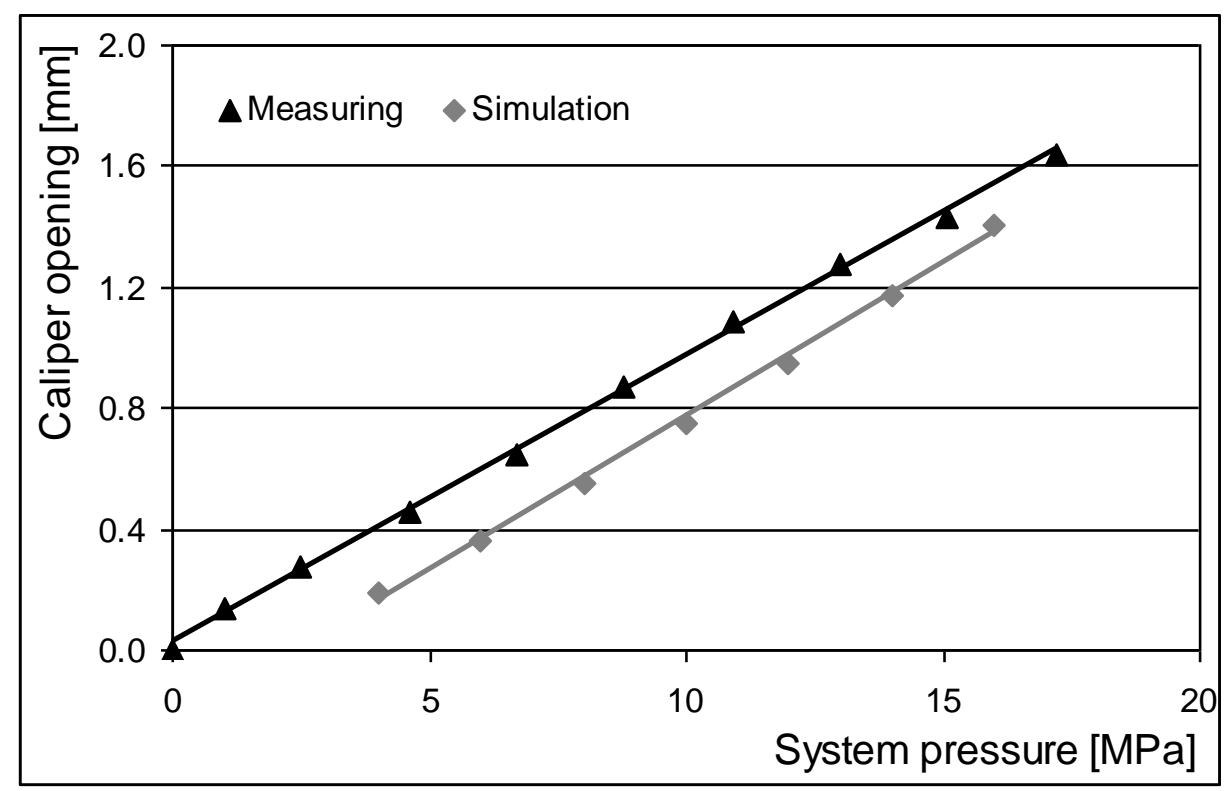

Figure 6. Measuring and simulation results of the dangerous cross-section.

It can be seen in the figure that there is a linear connection between the pressure increase and the opening, however the position of the two straight line and their angle closed with $\mathrm{x}$-axis neither agree. Based on this we had to change both on the boundary conditions and on the material models in the finite element surroundings. The result of these the new simulation results got covered with the measuring results (Figure 7.).

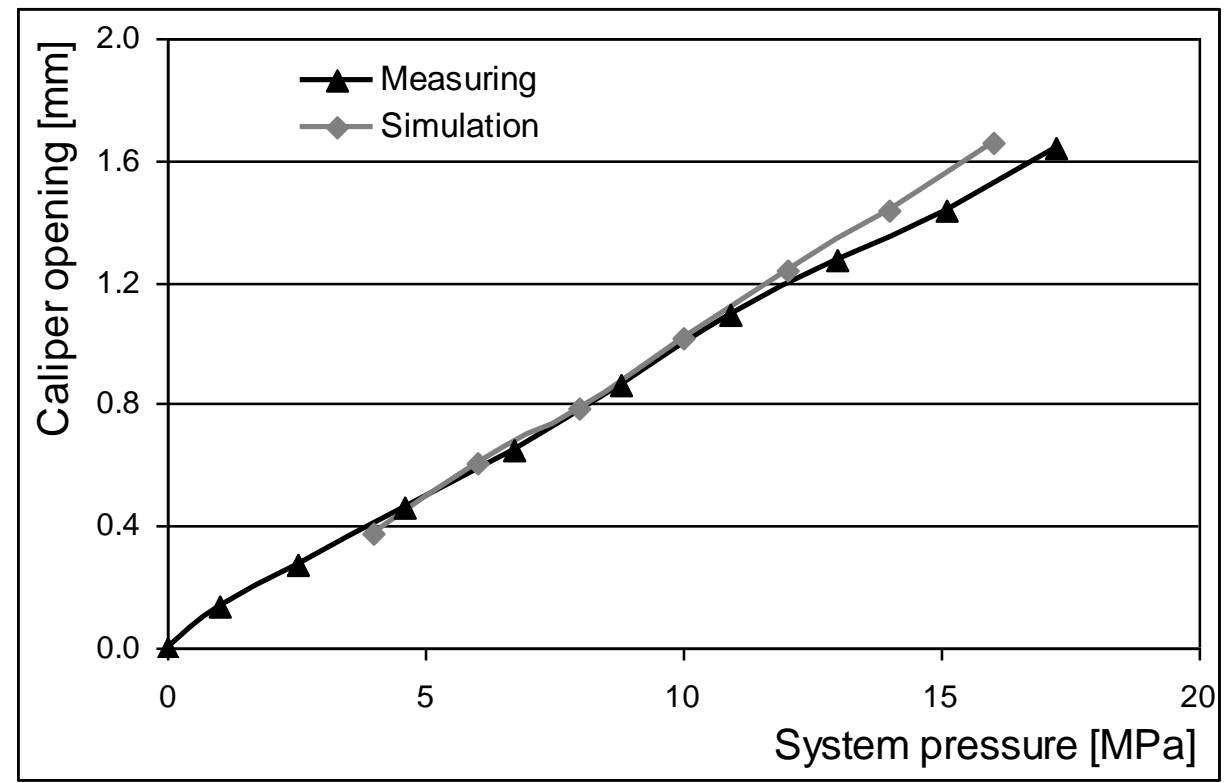

Figure 7. Comparing the identificated finite element surroundings and the measuring results.

This step is extremely important surely the finite element simulation describes (models) the reality with greater safety in case of new brake caliper constructions produced further. Thus beside the manufacturing quickness produced by using the CAM software the finite element software guarantees the quick and reliable checking. The changes carried out in the 3D model in the CAD-system - the adjustment concerning the suspension of another rally racing car - the checking and production preparing processes need only a couple of hours. This is extremely important, well in case of rally cars their preparation to the next race (or to test) is limited in time. If solving the technical problems fails in time then the race has to be maybe missed which influences negatively the result reached in the season, too? 
It was necessary also to optimize the pad wear following the mechanical designing. This is a very complex process which planned developing process can be seen in Figure 8.

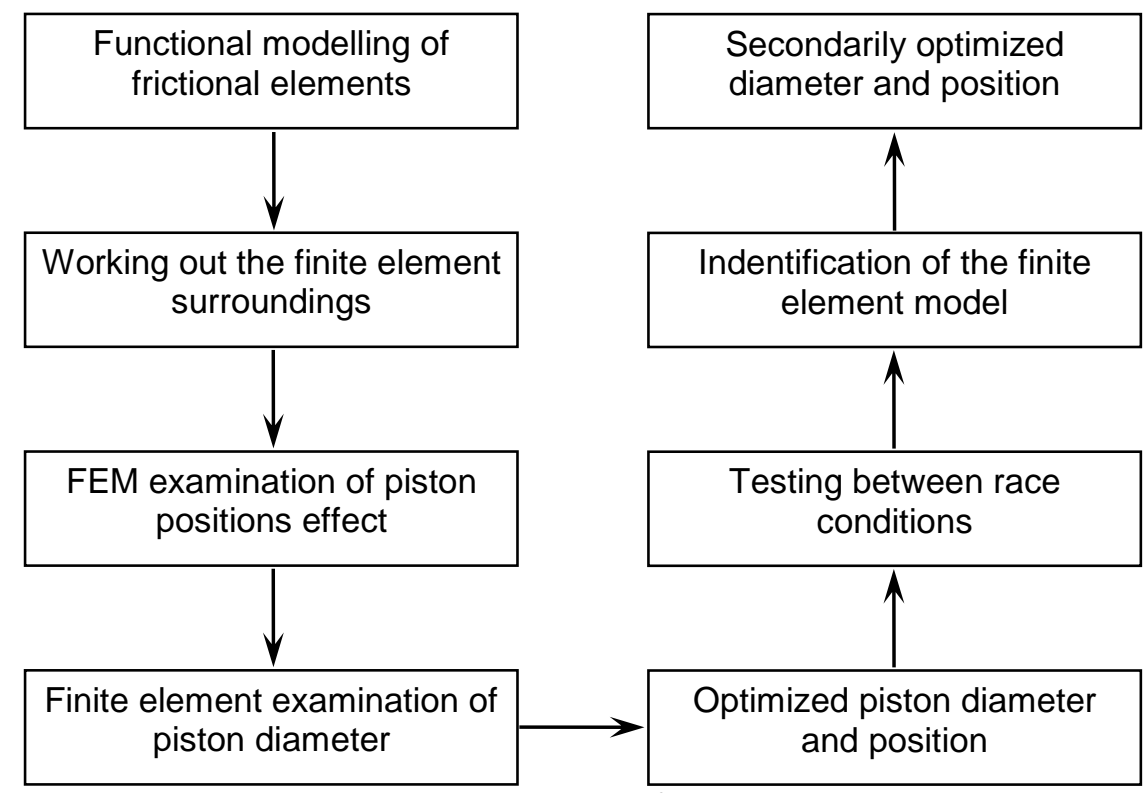

Figure 8. The planned process of developing pad wear.

More factors influence the brake pad wear during breakings, as for example the friction forces, the normal direction forces, the temperature, the speed conditions... In this case we focus to the normal direction force forming on the pistons, to the two friction forces rising on the brake pad respectively. We search the optimum of this system which means the uniform, pressure distribution (minimum deformation) between the brake pad and brake disc.

The pressure distribution between the brake pad and disc brake is neither uniform from more standpoints. The first reason is the aim that to avoid the warming up of the pistons the connecting surfaces of the piston and the brake pad should be as small as possible. Because of this the normal direction force $\left(F_{\text {normal }}\right)$ is passed on relatively small surface which is equalized only by the steel plate on the backside of the brake pad. Second reason is that the friction force $\left(F_{\text {friction }}\right)$ strives remove the brake pad into longitudinally (in Figure 9. the friction force component interpreted on the pad can be seen). To prevent this appropriate buffers are formed in the brake caliper, so longitudinally displacement not, only pressing force develops between the two surfaces.

A new friction force $\left(\mathrm{F}_{\text {friction2 }}\right)$ rises proportionally with this pressing force which impedes the brake pad further approach $\left(v_{\mathrm{pad}}\right)$ to the disc. To eliminate this it is indispensable that the last piston diameter should be larger concerning the rotation direction of the brake disc. The larger piston diameter means also higher normal force a part of which is transformed to overcome the friction force ${ }_{2}$ between the brake pad and brake caliper. The forces affecting the brake pad and the displacements respectively can be seen in Figure 9. Especially the deformation of the pad shows the pad wear during simulation. The wear there is the greatest where the deformation is the smallest, namely these surface are those which contact the brake disc. The larger surfaces don't touch it to the effect of greater deformation, for example which also rises at supporting the pad laterally, or result lower surface pressure (Figure 10.). It is not allowed to forget that the deformation along $Y$-axis gives similar result as the normal direction stress (Figure 11a.) but this doesn't agree with the picture of the greatest reduced stress because of the friction forces (Figure 11b.). 


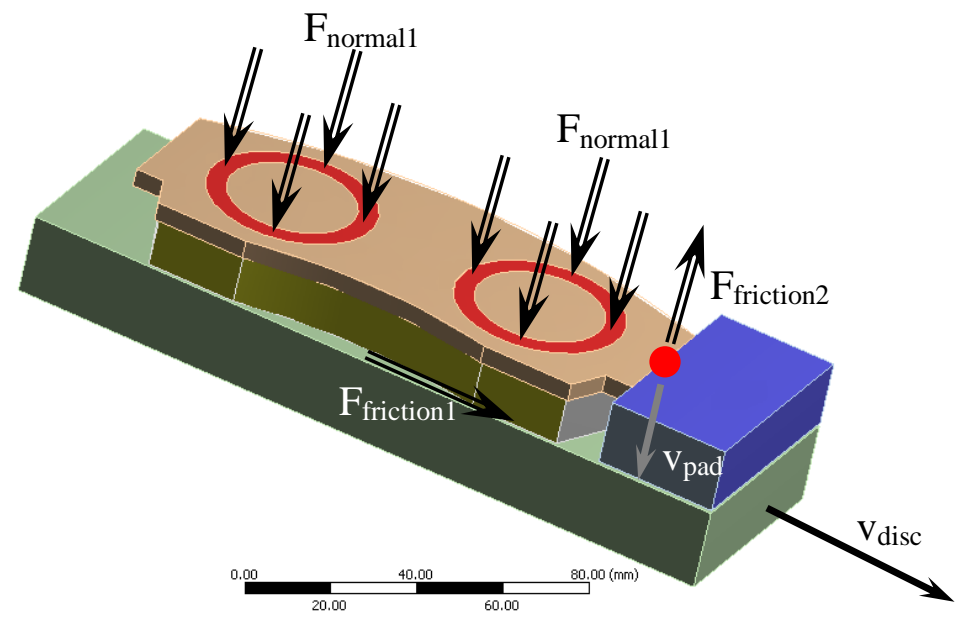

Figure 9. Forces affecting the brake pad and the deformations.

\section{Directional Deformation}

Type: Directional Deformation ( $Y$ Axis ) Unit: $\mathrm{mm}$

Time: 1

2011.11.02. 21:05

\begin{tabular}{|l}
$\mathbf{0 , 0 0 0 9 3 2 9 8}$ Max \\
0,00078135 \\
0,00062973 \\
0,0004781 \\
0,00032647 \\
0,00017485 \\
$2,3221 \mathrm{e}-5$ \\
$-0,00012841$ \\
$-0,00028003$ \\
$\mathbf{- 0 , 0 0 0 4 3 1 6 6}$ Min
\end{tabular}

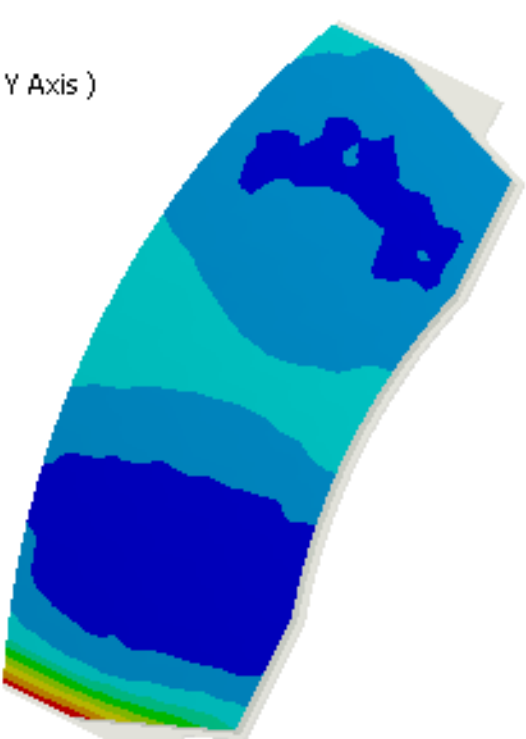

Figure 10. Geometric deformation of a given brake pad.

Normal Stress

Type: Normal Stress ( Y Axis)

Unit: MPa

Time: 1

2011.11.02. 20:04

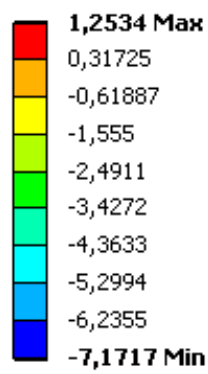

a,

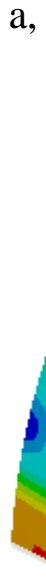

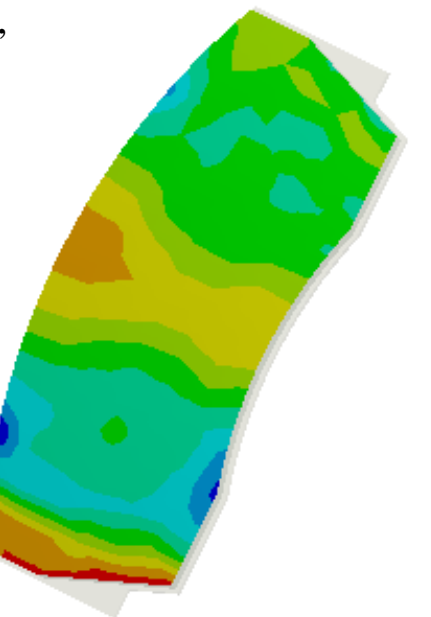

Equivalent Stress

Type: Equivalent (von-Mises) Stress Unit: $\mathrm{MPa}$

Time: 1

2011.11.02. 18:22

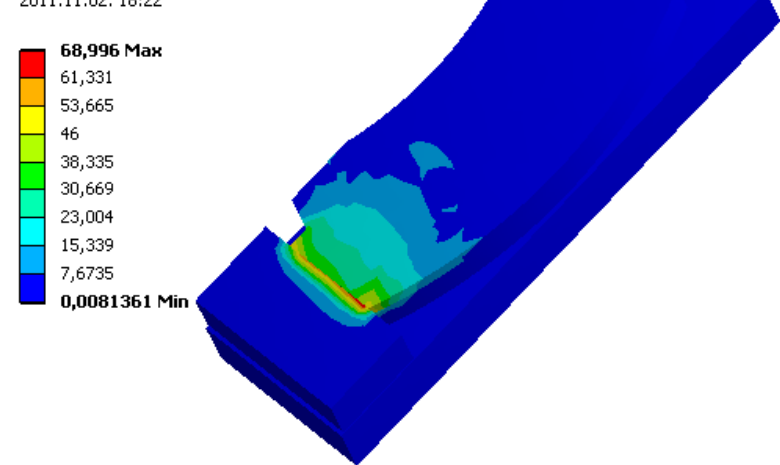

Figure 11. Normal direction stress of the brake pad (a) and its reduced stress (b). 
Based on these results we have run more simulations in which we changed the position of pistons and its magnitude. We experienced that choosing proper piston diameters we got more uniform stress distribution than asymmetrical placing of the pistons. These simulations are made nowdays, so determining the optimal piston diameter is still in progress. After closing the finite element simulations a further prototype brake caliper is made which we shall test already under racing conditions, too. However forming the tendentions abrasive process a lot of operation hours are needed, because of this the use of finite element simulations is appreciated mainly after forming identificated tribological finite element surroundings.

\section{$4 \quad$ SUMMARY}

During rally racing not only the acceleration but the deceleration have got extreme importance, too. Reaching the proper brake output also enjoys priority concerning the personal and property safety beside this.

There is a market demand because of the individual suspension and greater brake output for the brake caliper made by individual production. Another important market standpoint is that between the order and the delivery of the brake caliper to the customer minimal time can be. To satisfy these demands we have developed a designing-checking-manufacturing system which guarantees beside extremely short transit time the easy manageability of the changes. Nevertheless it is able to carry out the reliable mechanical changing of individual brake calipers by finite element simulation. This safety can be thanked that we compared the real deformation after manufacturing the prototype with the result of simulation, that we changed until the they were equal exactly with each other.

During development we also started tribological research, where we would like to optimize the wear of brake pad. We have established that to determine properly the dimension of pistons is a better method than to form asymmetric piston positions. In order to determine the optimal diameters we carry out further finite element simulations before manufacturing the newer prototype.

\section{$5 \quad$ ACKNOWLEDGEMENT}

We thank for the active, professional help given by the Gépész Tuning Ltd.

\section{REFERENCES}

[1] Richard Fischer, Rolf Gscheidle, Uwe Heider, Berthold Hohmann, Wolfgang Keil, Jochen Mann, Bernd Schlögl, Alois Wimmer, Günter Wormer (2009): Fachkunde Kraftfahrzeugtechnik, chapter 18th, Europa-lehrmittel Haan-Gruiten, 475-500 p.

[2] DIN 74000 (1992): Hydraulic braking systems; dual circuit brake systems; symbols for brake circuits diagrams

[3] Remsa (2008): Catalog. Eurofren Brakes S. L. U.: Ombatillo 530-610 p.

[4] Jensen Competition (2008): Jensen Competition Cataloge 2008/2009. Jansen

Competition $\mathrm{GmbH}$ : Ruprechtshofen 72-103 p.

[5] Kronprinz (2003): Wheel Catalog, KRONPRINZ GmbH, Solingen, 2-182 p.

[6] ISA-Racing (2006): ISA-Racing Catalog, Kottenheim 48-65 p

[7] Artech: Artech Typenliste 2002/2. Artech Leichtmetallrader GmbH: Herborn-Hörbach 4$375 p$

[8] www.matweb.com 